\title{
Regulating the Linkage of Mortgages
}

\author{
${ }^{1}$ Yaffa Machnes and ${ }^{2}$ Elia Chaba \\ ${ }^{1}$ Professor, Graduate School of Business Administration, Bar-Ilan University, \\ Ramat-Gan, 52900 Israel. \\ ${ }^{2}$ C.P.A., Ph.D, Bank International, Tel-Aviv, Israel.
}

\begin{abstract}
In the first 50 years of Israel's existence, most financial transactions were linked to the Consumer Price Index, since the nascent economy suffered from chronic inflation. This trend has changed in the last ten years, along with the low inflation rate. Currently, most loans are linked to the fluctuating interest rate. In May 2011, the Supervisor of Banks, from the Central Bank, the Bank of Israel, imposed controls on the mortgage system by limiting the percentage of the mortgage linked to the Inter Bank rate to one third of the debt. This regulation can be explained by the difference in attitudes toward risk estimates on the part of the Bank of Israel as compared to debtors. This paper discusses classical measures of risk such as standard deviation, skewness and kurtosis that are often implemented by debtors, and the value at risk (VAR) estimates that were used by the Supervisor of Banks. These measures account for the new regulation imposed on mortgage banks.
\end{abstract}

Keywords: interest rate linkage, mortgage, Consumer Price Index, Supervisor of Banks, Bank of Israel, Interbank rate.

\section{Introduction}

Fluctuations in interest rates have prompted banks all over the world to curtail loans at a fixed interest rate and to encourage loans whose return is linked to changes in the credit markets. In Israel, banks lend money in a variety of linkage lines. The hyperinflation that hit the economy in the 80's induced linkage to the Consumer Price Index (CPI) as regards most monetary transactions. The CPI index is published in the middle of each month with data on the previous month. At present, the most common linkages are the CPI and the Prime rate, which is estimated as the inter-bank interest rate plus $1.5 \%$. Over the last decade, as interest rates have gone down, the linkage of "short term" debt to the Prime rate has become more popular.

A follow-up of all consumers who obtained credit from one bank in Israel between 2004-2007 shows that in this period of time, only $27 \%$ of the debtors borrowed money linked to the CPI and this kind of debt only accounted for $15 \%$ of the total debt. The other loans were not linked to CPI and most were linked to the Prime rate. (Chaba, 2011). Data sets from the central bank, The Bank of Israel, based on reports by the seven largest banks that lend more than $90 \%$ of the total Israeli bank credit, show that from 1999 to2010, $86 \%$ of the debt that was not linked to the CPI was linked to the prime rate and only $14 \%$ of the credit that was not linked to the CPI was borrowed at a fixed interest rate without any linkage.

In May 2011, the Supervisor of Banks from the Central Bank, the Bank of Israel issued a new regulation to the mortgage banks, limiting the percentage of mortgage loans linked to the Prime rate to only one third of each loan.

This paper explains the difference in the way risk is perceived and treated by debtors and by the Comptroller. 


\section{Interest Rates}

The Bank of Israel publishes data on the monthly average quoted interest rate. The daily CPI return from government bonds which serves as the basis for the CPI linked interest rate that banks charge their customers is also available. These data cover loans made to consumers over a period of 216 months from 1993 to 2010.

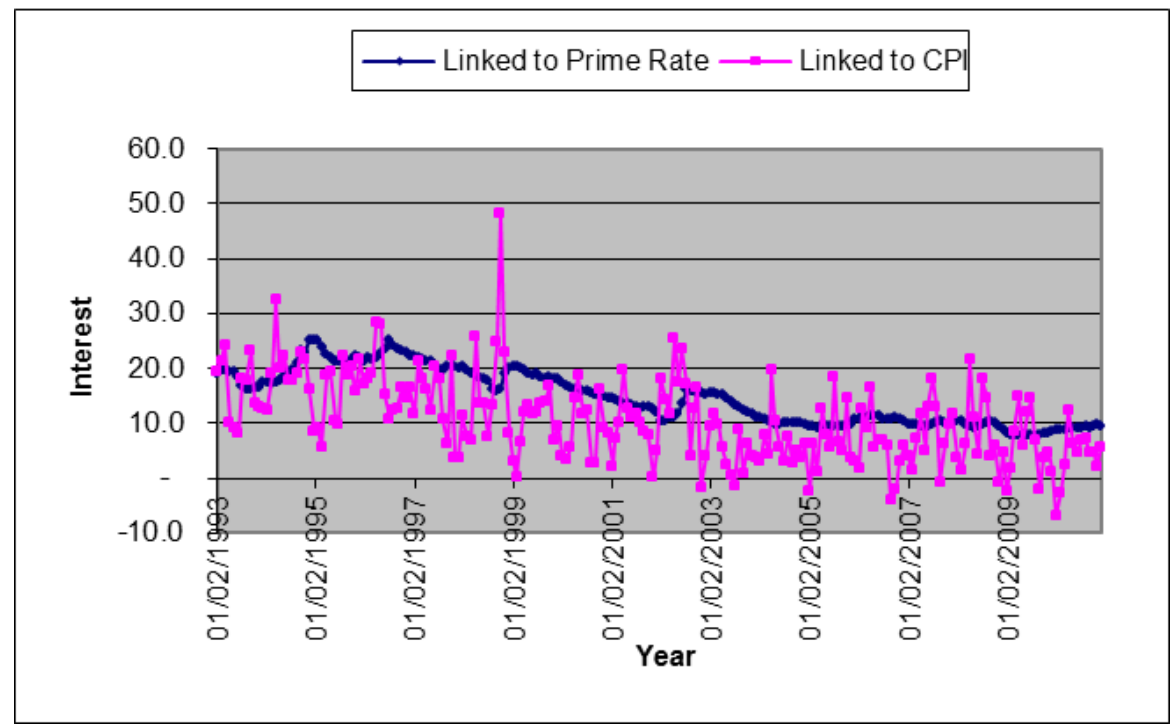

Fig. 1: Monthly average interest rate by linkage (estimated per annum).

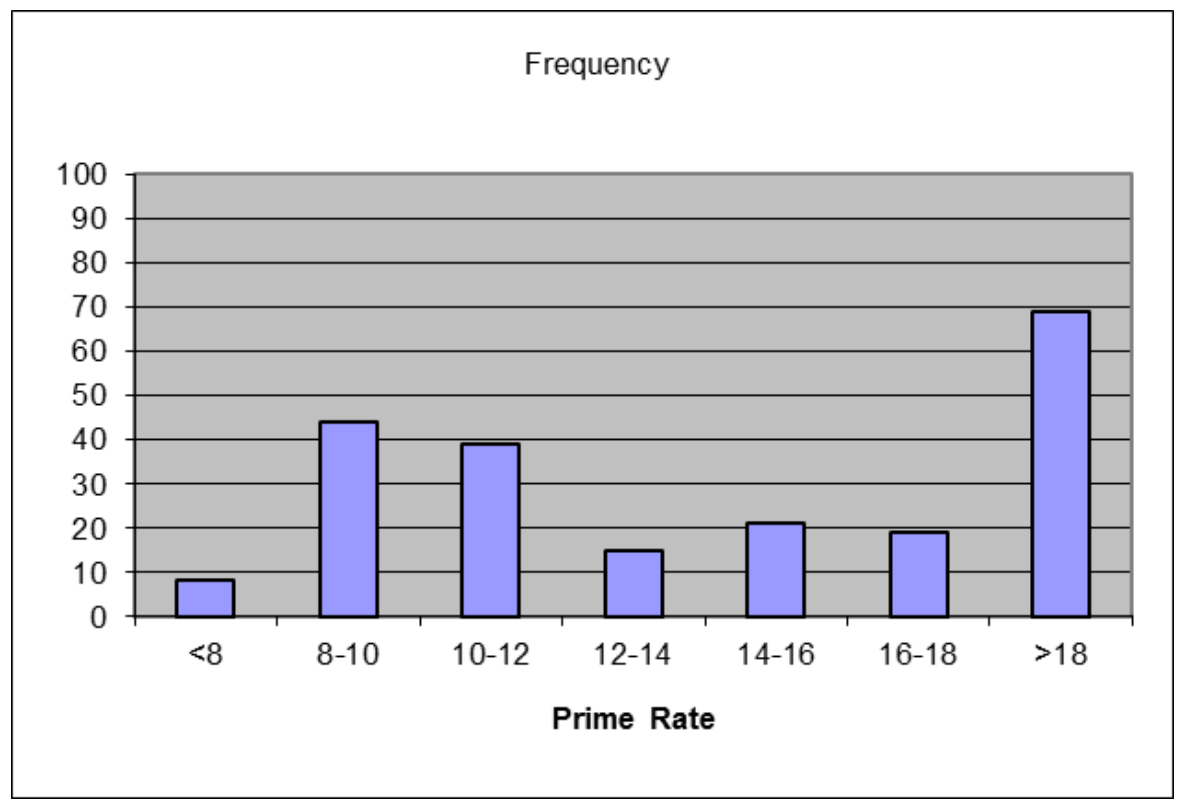

Fig. 2: Statistical Distribution of the prime rate 


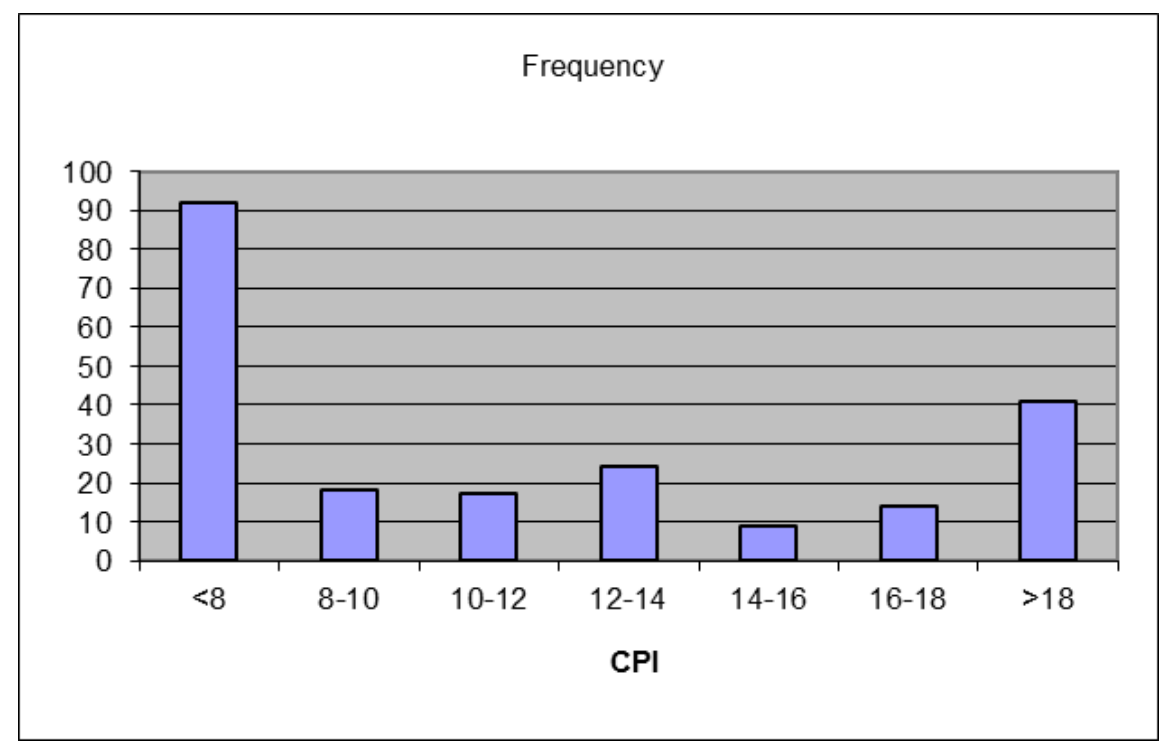

Fig. 3: Statistical Distribution of the CPI+ interest

On the basis of these data we estimated the following parameters:

TABLE I: Interest rates- monthly data, 1993-2010.

\begin{tabular}{|l|l|l|}
\hline & $\begin{array}{c}\text { CPI indexed+Interest } \\
1993-2010\end{array}$ & $\begin{array}{c}\text { Interest linked to the Prime } \\
\text { rate, 1993-2010 }\end{array}$ \\
\hline Average & 10.62 & 14.76 \\
\hline Standard deviation & 7.6 & 4.99 \\
\hline Skewness & 0.78 & 0.33 \\
\hline Kurtosis & 1.86 & -1.22 \\
\hline VAR $^{5}$ Value at Risk-5\% & $20.96 \%$ & $23.09 \%$ \\
\hline VAR: Value at Risk-10\% & $18.2 \%$ & $21.84 \%$ \\
\hline Correlation coefficient: & 0.46 & \\
\hline
\end{tabular}

We estimated these parameters once again for a shorter period from 2002 to2007 for customers who were unable to recall data for the last 18 years, and whose behavior was studied by Chaba from 2004 to 2007. The estimations of skewness and kurtosis were not statistically significant for this shorter period.

TABLE II: Interest rates- monthly data, 2002-2007.

\begin{tabular}{|l|l|l|}
\hline & $\begin{array}{l}\text { CPI indexed+Interest } \\
2002-2007\end{array}$ & $\begin{array}{l}\text { Interest linked to the } \\
\text { Prime rate }(\mathrm{PR}) \text { 2002- } \\
2007\end{array}$ \\
\hline Average & 7.58 & 11.44 \\
\hline Standard deviation & 6.28 & 2.12 \\
\hline VAR: Value at Risk-5\% & NA & $15.7 \%$ \\
\hline VAR: Value at Risk-10\% & $8.8 \%$ & $15.3 \%$ \\
\hline
\end{tabular}

\section{Risk Measures}

Customers want to choose an efficient portfolio and attempt to maximize the coefficient of variation; i.e., the ratio of the average cost of their total debt to its standard deviation. The interest indicates the value of the debt 
whereas its mean cost is the reciprocal of the interest charged. Thus customers consider the actual interest rate which was around $3 \%$ and look at the standard deviation, skewness and kurtosis inequalities

$$
\sigma \mathrm{CPI}>\sigma \mathrm{PR}
$$

The actual figures for these parameters of inequality (1) for the period between 1993 and 2010 are 7.6>4.99

The estimation for the six years period from 2002 to 2007 reveals a much greater difference between the inequality ratios (1): $6.28>2.12$

According to these estimates, customers believe there is a greater risk associated with the CPI indexed loan and choose to pay higher interest for the debt linked to the prime rate in an attempt to reduce their risk. Additional measures such as skewness, estimated as 0.78 for the CPI indexed loan relative to 0.33 for the prime linked debt point to asymmetry of the distribution and to a greater frequency of a higher cost of debt for the CPI linkage. The estimates of kurtosis also point to a greater risk of the CPI indexed debt. It was estimated to be 1.86 for the CPI linked rate as compared to -1.22 for the risk of debt linked to the prime rate. The positive correlation coefficient between the two types of debts, estimated as 0.46 , reduces the rationale to borrow in both of these types of linkage.

\section{The Supervisor of Banks Point of View}

The Supervisor of Banks has access to all data about the interest rate paid to banks by their customers. The research division of the Central Bank is doubtless familiar with the statistical measures presented in Tables 1 and 2. In addition, the Central Bank has access to data about the total amount of debts for all borrowers in the Israeli financial industry. The data show that the interest rate for mortgages was usually $1 \%$ lower than loans granted for other reasons. The Bank of Israel publishes additional data about all mortgages contracted by Israeli banks during the year. It was found that $11 \%$ of the borrowers use more than half of their income to pay their monthly mortgage. One third of the loans that were taken out as mortgages amount to $60 \%-75 \%$ of the purchase price of the house. The Bank of Israel reported that in April 2011, 47\% of all mortgages were linked to the Prime rate. The Supervisor of Banks acts to ensure that debtors will be able to pay their mortgages and at the same time to protect mortgage banks from failures. In Israel, the government does not guarantee bank deposits. Since mortgage debt is not paid in one period, the risk should not be measured by statistics involving the standard deviation, skewness and kurtosis alone. As a result of the Basel regulations, as discussed by Linsmeier (2000), the Supervisor of Banks was concerned that interest rate would increase in the future to such a level that many debtors would be unable to pay their mortgage. Thus, he looked at the VAR of historical interest rates and decided to limit the percentage of debts linked to the Prime rate.

Tables 1 and 2 show the different ways debtors and the regulator assess risk. While customers look at classical measures of risk, the regulator is more concerned about the VAR. The standard deviation does not worry him, since debtors do not pay back the whole loan in one period. Any monthly fluctuations will affect the monthly payment, which amount in many cases to a large fraction of the debtors' income and thus rescue the mortgage banks.

\section{References}

[1] Chaba, E., Trends in the Insurance Industry and with Private Credit Customers in the Israeli Economy, Ph.D. Dissertation. Bar-Ilan University, Israel, 2011.

[2] Bank of Israel, www.bankisrael.gov il/press/heb/110627/110627r.doc, accessed 10 December 2015.

[3] http://www.boi.gov.il/deptdata/monetar/shukhon/shhd04ah.xls, accessed 1 January 2012.

[4] YNET, 16/ 11/2011, (Internet news, in Hebrew).

[5] Linsmeier, T.J. and Pearson, N.D., Value at Risk, Financial Analysts Journal 56(2): 47-67, 2000. pp. 47-67. 